\title{
Structural, Opticaland Morphological Properties Of Zn And Mg Co-Doped V20sthin Filmnanostructures
}

\author{
Sandesh Kumar Rai ${ }^{1,2, *}$, Rajesh Rai ${ }^{3}$, Raghavendra Bairy ${ }^{4},{\text { Jayarama } A^{5}}^{5}$ \\ ${ }^{1}$ Department of Mechanical Engineering,Canara Engineering College, Mangalore- 574219, India \\ ${ }^{2}$ Regional ResearchCenter, Visvesvaraya Technological University, Belagavi-590 018, India \\ ${ }^{3}$ Department of Mechanical Engineering, A.J.Institute of Engineering \& Technology, Mangalore - 575006, India \\ ${ }^{4}$ Department of Physics, NMAM Institute of Technology, Nitte, Karkala - 574110, India. \\ ${ }^{5}$ Department of Physics, Alvas Institute of Engineering \& Technology, Moodbidri - 574225, India \\ Corresponding author*: Mr Sandesh KumarRai, \\ AssistantProfessor, \\ Department of Mechanical Engineering, \\ Canara engineering college- 574110, Karnataka, INDIA,
}

Article History: Received: 11 January 2021; Accepted: 27 February 2021; Published online: 5 April 2021

\begin{abstract}
The research study reveals metallic co-doping of Zinc(Zn) and Magnesium (Mg) on vanadium pentoxide $\left(\mathrm{V}_{2} \mathrm{O}_{5}\right)$ thin film nanostructures by spray pyrolysis deposition technique. The studyfindings have been made into how the morphological, structural and optical properties of the materials change for the different codoping percentage of $1 \%, 3 \%, 5 \% 10 \%$ of $\mathrm{Zn}-\mathrm{Mg}$. X-ray diffraction (XRD)clearly showsan orthorhombic crystalline structure with polycrystalline nature. The dopantZn and Mginfused into the $\mathrm{V}_{2} \mathrm{O}_{5}$ matrixand is confirmed by EDAX images. A field emission scan electron microscope was used to examine surface morphology whichreveals that grain structure has beenmodified by increasing the doping content. It is evident from theatomic force microscopy (AFM) images that the effect of $\mathrm{Zn}$ and $\mathrm{Mg}$ on $\mathrm{V}_{2} \mathrm{O}_{5}$ thin filmshave enhanced surface roughness. The transmittance and energy bandgap (Eg) of the film found to be decreased with an increase in doping concentration whereas absorbance varieswith doping levels. The research findings suggest that the $\mathrm{Zn}-\mathrm{Mg}$ co-doped $\mathrm{V}_{2} \mathrm{O}_{5}$ thin films could be a potential source for energy,optical and sensor-based device applications.
\end{abstract}

Keywords: Spray Pyrolysis; Co-doped $\mathrm{V}_{2} \mathrm{O}_{5}$; XRD;Crystallinity; FESEM;Surface morphology.

\section{INTRODUCTION}

The advancement in the field of nanomaterialslike transition metal oxides $\mathrm{V}_{2} \mathrm{O}_{5}$ and their physiochemical properties has attracted the attention of researchers in recent years[1-4].

The area of application of metal oxide-based $\mathrm{V}_{2} \mathrm{O}_{5}$ devicesis mainly in storage devices, UV detectors, sensors, electro-optical devices, energy harvesters,transistors, piezoelectric devices etc. $\mathrm{TheV}_{2} \mathrm{O}_{5}$ propertieslike electrical resistivity,n-type conductivity, magnetic susceptibility,high specific power, transmission, high energy density, variable oxidation statesof $\mathrm{V}_{2} \mathrm{O}_{5}$ make the above applications possible [5-14].

Recent researches on various oxides of vanadium ions could vary the properties by anoxide surface formation and chemisorption [15-18]. The electric conductivity of $\mathrm{V}_{2} \mathrm{O}_{5}$ will enhanceduring interaction with reducing gases during which $\mathrm{V}^{5+}$ species changes to $\mathrm{V}^{4+}$. The concentration of oxygen nonstoichiometric $\left(\mathrm{V}_{2} \mathrm{O}_{5-\mathrm{x}}\right)$ due to oxygen vacancies are responsible for the semiconducting properties of $\mathrm{V}_{2} \mathrm{O}_{5}$

Doping is a key part of evaluating the physical properties and uses of semiconductors. This concept has been empirically demonstrated by evidence-based applications in the industries of semiconductors.Minor proportions of impurities affect the carrier ions and electrical conductivity of substances. The solution of bipolar doping and compensation problems in semiconductors is proposed for co-doping. Co-doping in particularcan be effective in improvingthe solubility of dopant, increasing activation rates by reducing acceptors and donorsionising energies and increasing carrier mobility [19,20].

Zinc and magnesium were added to enhance the optical, structural, electrical and morphological properties of $\mathrm{V}_{2} \mathrm{O}_{5}$ thin film. Both $\mathrm{Znand} \mathrm{Mg}$ ions easilyenter intothe $\mathrm{V}_{2} \mathrm{O}_{5}$ crystal lattice and substitute the $\mathrm{V}^{2+}$ position of the crystal because the ionic radius of these transition metals element which aresubstantially lower than that of $\mathrm{V}^{2+}$.

The spray pyrolysis thin film deposition method is followed tostudy how a $\mathrm{Zn}$ and $\mathrm{Mg}$ co-doping allows easy control and replace desired elements within required amountsinthe precursor solution and affects the morphological, microstructuraland optical properties of $\mathrm{V}_{2} \mathrm{O}_{5}$ thin films.

The grain size and crystallinity of the thin films will decide the selectivity and sensitivity of a gas sensor which is measured in terms of change in the resistivity of a gas when it comes in contact with an oxide layer [21]. 
Considering this co-doping by spray pyrolysis method is ideally suited for thin film deposition based on $\mathrm{V}_{2} \mathrm{O}_{5}$.

It is important to find new appropriate doping substances that do notchange much of the structure of the $\mathrm{V}_{2} \mathrm{O}_{5}$ crystals to obtain $\mathrm{V}_{2} \mathrm{O}_{5}$ thin film which hasa wide optical band gap with improved electrical conductivity.Thework is focused on the fabrication and study ofstructural properties ofZnand Mgco-doped for the development of devices on sensors andenergy-basedapplications.

\section{EXPERIMENTAL WORK}

\subsection{SamplePreparation}

The thin films of pure $\mathrm{V}_{2} \mathrm{O}_{5}$ and $\mathrm{Zn}-\mathrm{Mg}$ co-dopedwithvarying percentages in equal volumes were fabricated by spray pyrolysismethod on substrate material like glass.[22]. Theconcentrated $\mathrm{HCl}$ is added in drops to ammonium metavanadate in $100 \mathrm{ml}$ distilled water witha concentration of $0.02 \mathrm{M}$, the standard solution of $\mathrm{V}_{2} \mathrm{O}_{5}$ was prepared.By adding $\mathrm{V}_{2} \mathrm{O}_{5}$ precursor solutions with magnesium chloride $\left(\mathrm{MgCl}_{2}\right)$ andZinc acetate $\left(\mathrm{Zn}\left(\mathrm{CH}_{3} \mathrm{COO}\right)_{2} 2 \mathrm{H}_{2} \mathrm{O}\right)$ in equal quantities, $\mathrm{Zn}-\mathrm{Mg}$ co-doped thin films of $1 \%, 3 \%$, 5\% and $10 \%$ concentrations were fabricated. The solution is continuously sprayed on the well-purified glass substrate surfaceat $350^{\circ} \mathrm{C} .[23]$

Theconditions for depositing the thin films on glass substrate are listed in table 1 . The thickness of approximately $\sim 200 \mathrm{~nm}$ of thin films was prepared and maintained for about $350{ }^{\circ}$ Cfor about one hour in a heated air oven to clear other impure residualsthat exist in the solutions.

Table 1: Thin film depositionparameters pure $\mathrm{V}_{2} \mathrm{O}_{5}$ and $\mathrm{Zn}-\mathrm{Mg}$ co-dopedthin films by spray pyrolysis

\begin{tabular}{|l|l|}
\hline Spray Parameters & Optimum Values \\
\hline Glass substrate temperature & $350^{\circ} \mathrm{C}$ \\
\hline Ammonium metavanadate & $0.02 \mathrm{M}$ \\
\hline Solution concentration of Magnesium chloride & $0.02 \mathrm{M}$ \\
\hline Solution concentration of Zinc acetate & $0.02 \mathrm{M}$ \\
\hline Solvent & Deionised water \\
\hline Volume \% of Zn \&Mg in equal quantities & $1,3,5,10$ and 20 \\
\hline Air Pressure & $2 \mathrm{bars}$ \\
\hline Nozzle to substrate distance & $24 \mathrm{~cm}$ \\
\hline Solution spray rate & $1 \mathrm{ml} / \mathrm{min}$ \\
\hline Nozzle diameter & $0.8 \mathrm{~mm}$ \\
\hline Solution spray time & $\approx 10 \mathrm{mins}$ \\
\hline
\end{tabular}

\subsection{Characterization techniques}

The undoped $\mathrm{V}_{2} \mathrm{O}_{5}$ and $\mathrm{Zn}-\mathrm{Mg}$ co-doped $\mathrm{V}_{2} \mathrm{O}_{5}$ thin films thickness have beenmeasured bythe gravimetric weight differencemethod using the microbalance.An approximate $200 \mathrm{~nm}$ uniform thick films were fabricated by spray pyrolysis. The Bruker's XRD was used for measuring diffraction angle $2 \theta$ at a wavelength of $1.5406 \AA$. The microstructural particle in the film is analysed using FESEM images. The elemental composition is ensured by the EDAX spectrum and AFM images will help in the surface roughness measurement of films. The UV-visible spectrophotometerhelps in finding the optical bandgap (Eg),transmittance and absorption coefficient of the films.

\section{RESULTS AND DISCUSSIONS}

\subsection{XRD study}

X-ray Diffractometer through the precise range of $10^{\circ}$ to $75^{\circ}$ having the wavelength of $1.5406 \AA$ help in structural propertiesstudy of film and is shown in Figure 1. The XRDassociated with the planes $\left(\begin{array}{lll}2 & 0 & 0\end{array}\right)$ with diffraction angle $(2 \theta)=12.28^{\circ}$ indicate the polycrystallinity natureof films and are crystallized with orthorhombic structure. 
Fig. 1: $\mathrm{V}_{2} \mathrm{O}_{5}$ and $\mathrm{Zn}-\mathrm{Mg}$ co-dopedthin films $\mathrm{XRD}$ patterns

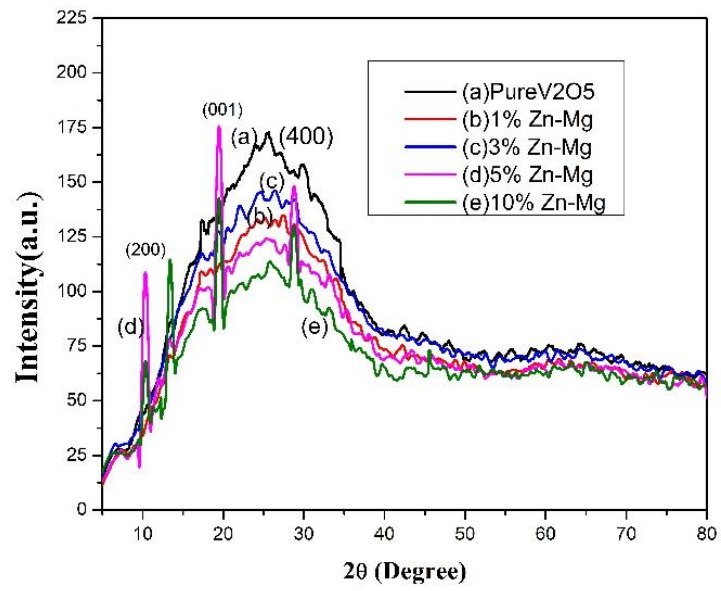

\subsection{Morphological properties study}

Microscopic characteristics of the prepared $\mathrm{Zn}-\mathrm{Mg}$ co-doped $\mathrm{V}_{2} \mathrm{O}_{5}$ thin films analyzed by FESEM has a huge impact on the thin film'sstructural properties.Figure. 2 (a-e) shows images of FESEMfor pure $\mathrm{V}_{2} \mathrm{O}_{5}$ and $\mathrm{Zn}$ $\mathrm{Mg}$ co-doped $\mathrm{V}_{2} \mathrm{O}_{5}$ thin films.

At $1 \%$ co-dopinguniform and evenly distributed $\mathrm{V}_{2} \mathrm{O}_{5}$ observed with very few doping of $\mathrm{Mg}$ and $\mathrm{Zn}$.For 3\% of codoping, a void was observed and the increased void content was founddifficult to handle.But with moredopantintegration, this structure transforms into a platue like structure which was visible in $5 \%$ and is increased compared to $3 \%$ co-dopant. The random distribution with a slight increase in surface roughness is visible here. As co-doping increased to $10 \%$, thesize and shape of co-dopantswere almost uniform and oriented in the same direction with high surface roughness. However, the concentrations of the dopants $\mathrm{Zn}$ and $\mathrm{Mg}$ ) increased the grain sizes of the films.

(a) Pure $\mathrm{V}_{2} \mathrm{O}_{5}\left(\right.$ b) $\mathrm{V}_{2} \mathrm{O}_{5}$ with $1 \% \mathrm{Zn}-\mathrm{Mg}$
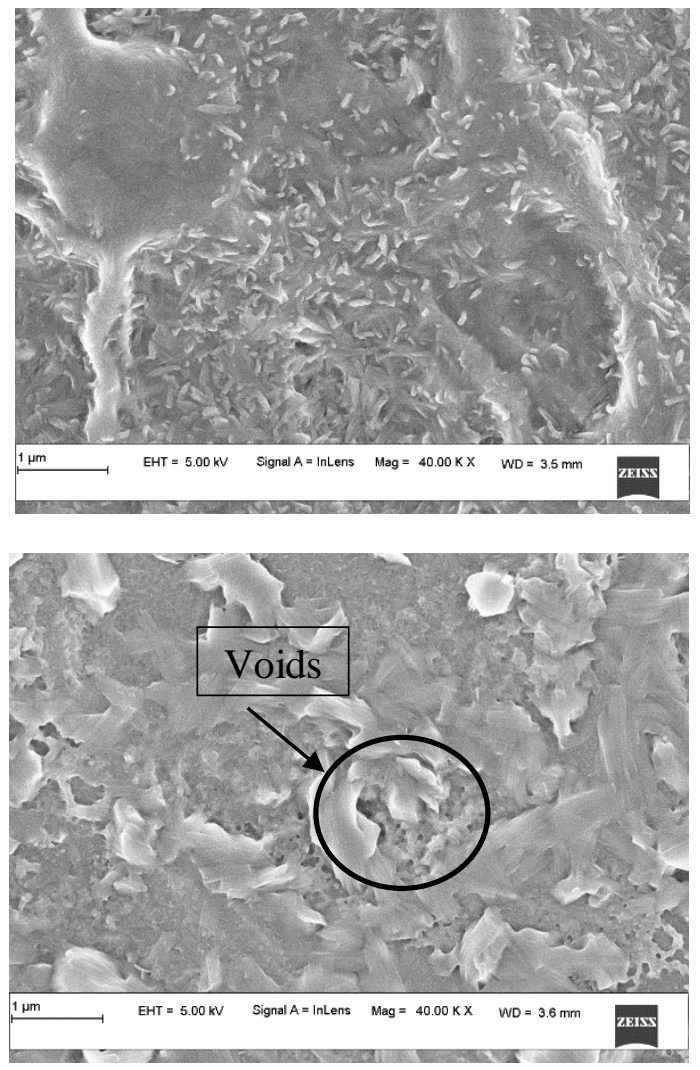
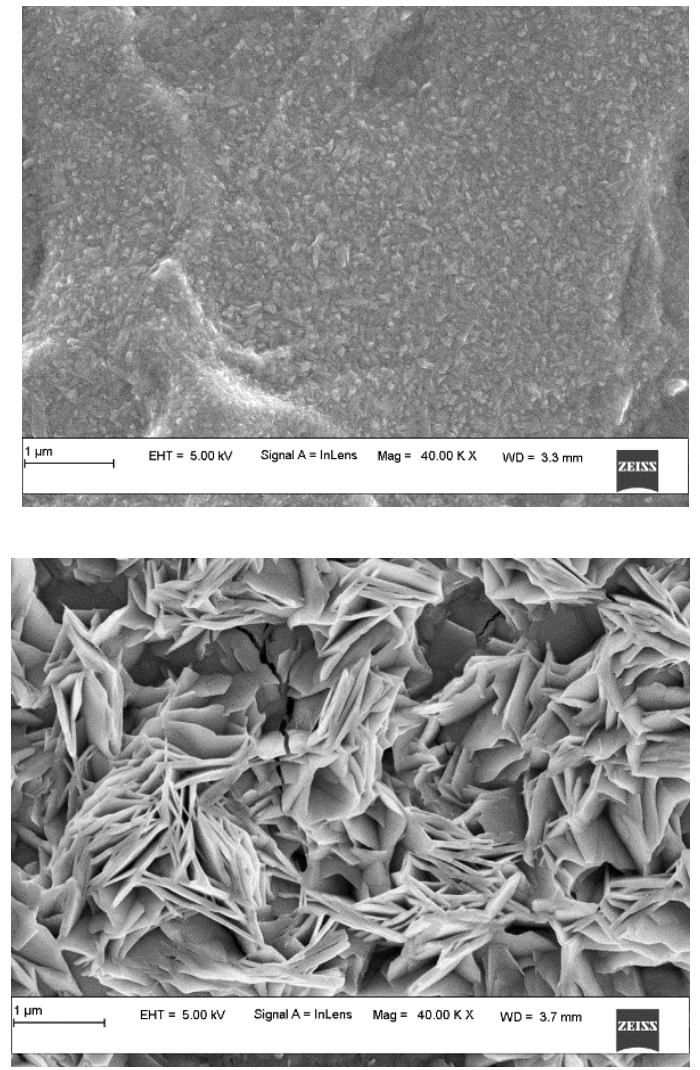
(c) $\mathrm{V}_{2} \mathrm{O}_{5}$ with $\left.3 \% \mathrm{Zn}-\mathrm{Mgd}\right) \mathrm{V}_{2} \mathrm{O}_{5}$ with $5 \% \mathrm{Zn}-\mathrm{Mg}$

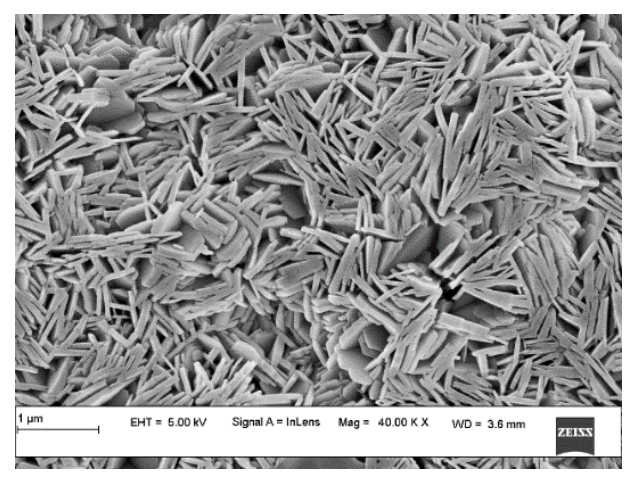

e) $\mathrm{V}_{2} \mathrm{O}_{5}$ with $10 \% \mathrm{Zn}-\mathrm{Mg}$

Fig. 2: FESEM images of a) pure $\mathrm{V}_{2} \mathrm{O}_{5}$ b) $1 \%$ c) $3 \%$ d) $5 \%$ and e) $10 \% \mathrm{Zn}$-Mgco-doped $\mathrm{V}_{2} \mathrm{O}_{5}$ thin films Thespectral peaks in the EDAX images have revealed the elements present in the prepared co-doped films and figure 3 showsthe presence of $\mathrm{V}, \mathrm{O}$, and co-dopants $\mathrm{Zn}$, and $\mathrm{Mg}$.

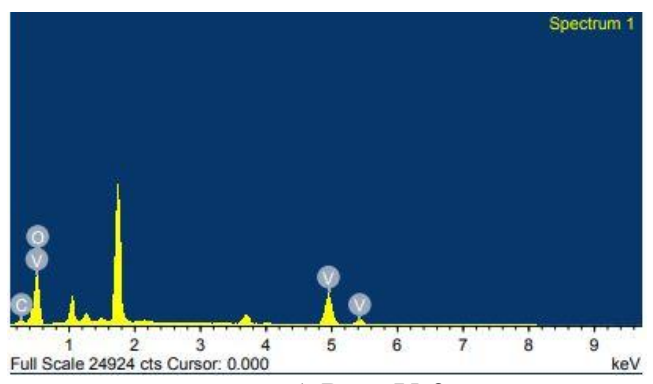

a) Pure $\mathrm{V}_{2} \mathrm{O}_{5}$

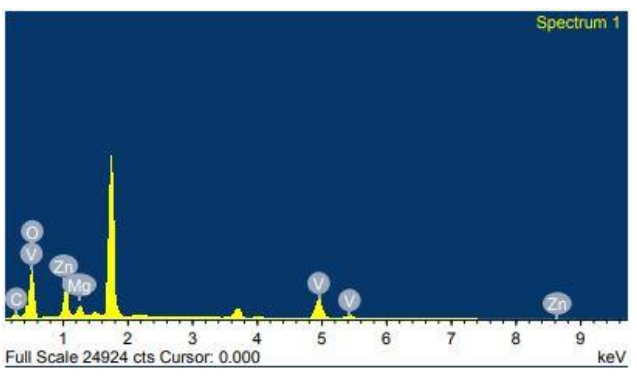

b) $1 \% \mathrm{Zn}-\mathrm{Mgco}-$ doped

Fig 3 (a) EDAX spectrum of (a) pure $\mathrm{V}_{2} \mathrm{O}_{5}$ and (b) Zn-Mgco-doped $\mathrm{V}_{2} \mathrm{O}_{5}$ thin films

\subsection{Optical properties analysis}

Electron transitions studiesof undopedand $\mathrm{Zn}-\mathrm{Mg}$ co-doped $\mathrm{V}_{2} \mathrm{O}_{5}$ thin filmshave been analyzed by absorption spectra and exhibits ultraviolet photons with their energy. Wavelengths in the range $300 \mathrm{~nm}-800 \mathrm{~nm}$ by UVVisible spectrophotometer is shown in figures 4 . The sudden decrease in absorbance with wavelengths while transmittance increases withwavelength wereobserved especially in the case of 3\%and 5\% co-doping which could be because of a change in crystallinity. It indicates that co-doping at other than these concentrations have little effect on crystal dimensions.
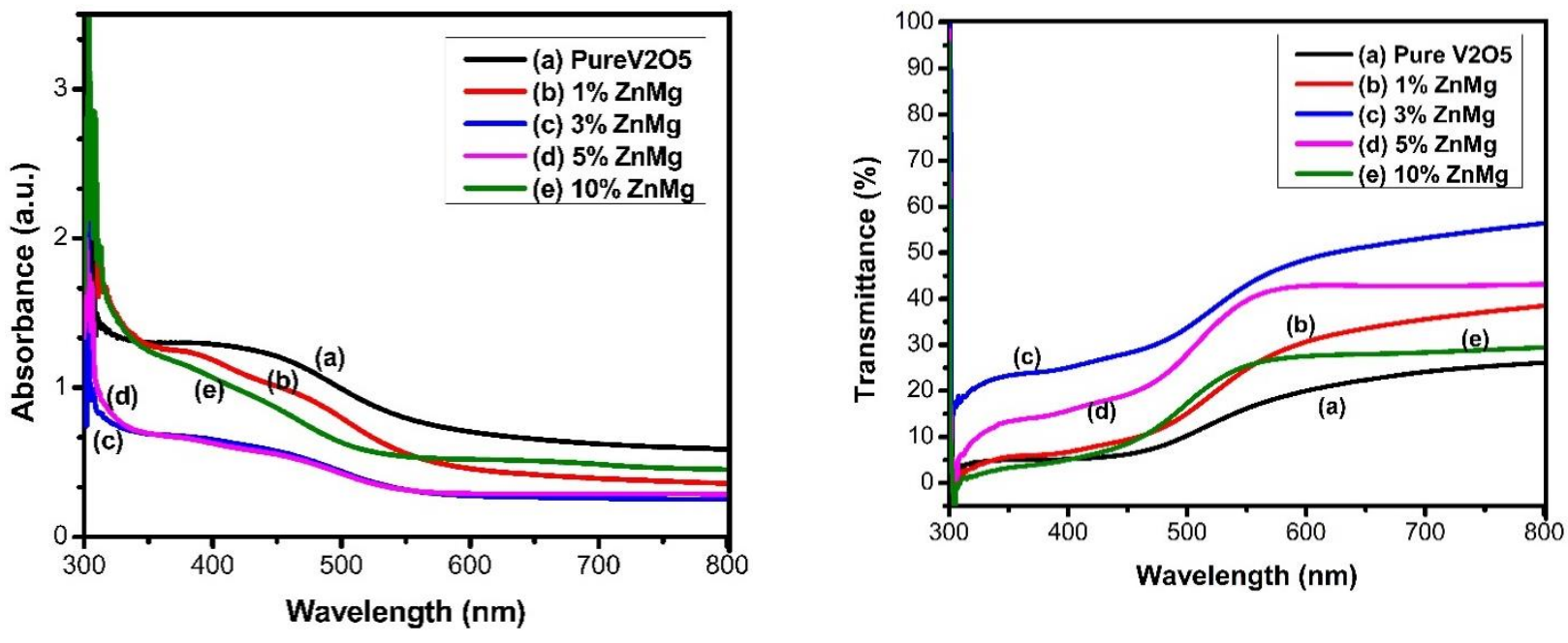
Fig. 4(a):Wavelength VsAbsorbance for the deposited $\mathrm{V}_{2} \mathrm{O}_{5}$ films and Fig. 4 (b):Wavelength Vs Transmittance for the undoped $\mathrm{V}_{2} \mathrm{O}_{5}$ and $\mathrm{Zn}$-Mgco-doped films.

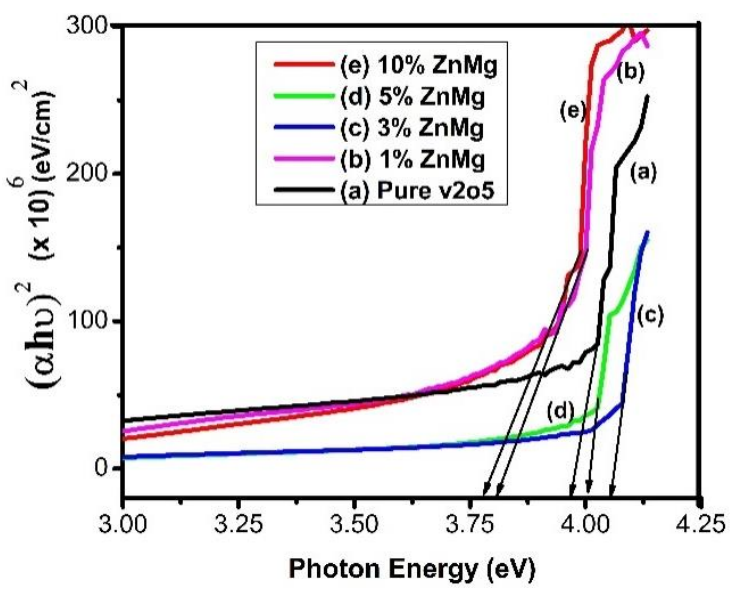

Fig. 5: Plot of $\alpha v^{2}$ Vs Energy (Eg) for $\mathrm{Zn}-\mathrm{Mgco}-$ doped $\mathrm{V}_{2} \mathrm{O}_{5}$ films.

The direct energy band-gap $\left(E_{g}\right)$ of the co-doped thinfilms were calculated by the tauc plot [24].The $E_{g}$ value in the range of $3.77 \mathrm{eV}$ to $4.07 \mathrm{eV}$ in $\mathrm{V}_{2} \mathrm{O}_{5}$ thin films for different co-doping concentration levels wasobserved which isshown in figure 5.The $\mathrm{E}_{\mathrm{g}}$ for pure $\mathrm{V}_{2} \mathrm{O}_{5}$ is $3.92 \mathrm{eV}$ however it is observed that the value decreases approximately to $3.80 \mathrm{eV}$ for $1 \%$ and $10 \%$ concentration. Egwillincrease for $3 \%$ and $5 \%$ co-doping concentration levels.It is clear that concentration levels $3 \%$ and $5 \%$ will play a major role in optical device applications and is useful in low band energy photovoltaic application.

\subsection{Atomic Force Microscopy (AFM) study}

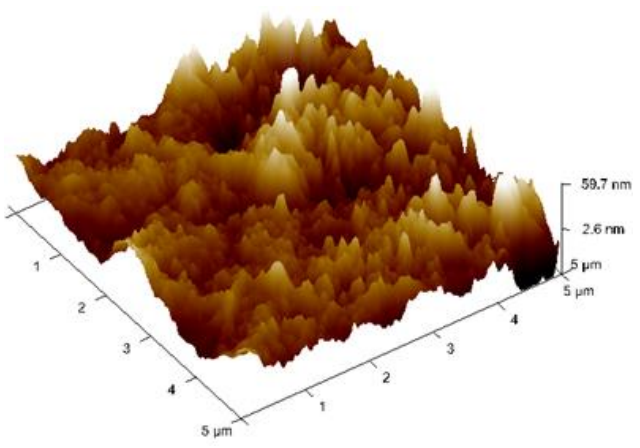

a)Pure

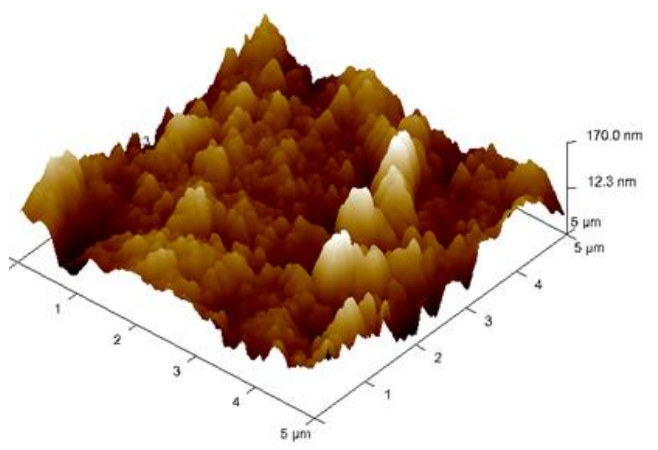

c) $3 \%$ dope of $\mathrm{Zn}-\mathrm{Mg}$

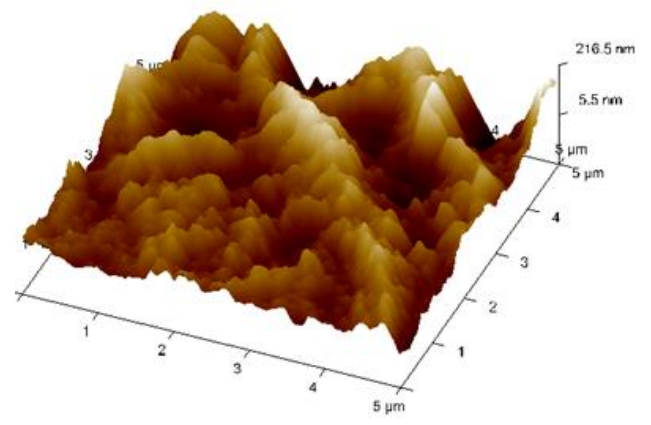

b) $1 \%$ dope of $\mathrm{Zn}-\mathrm{Mg}$

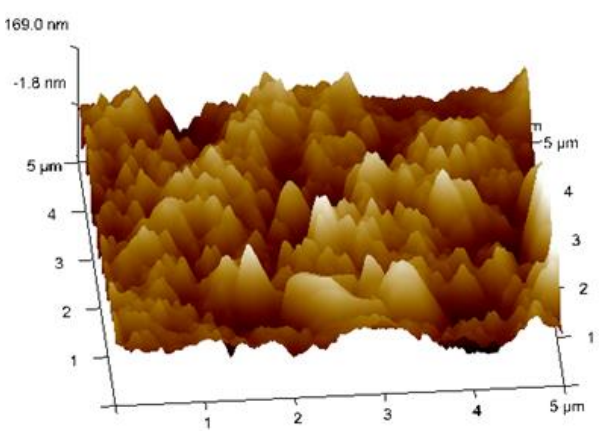

d) $5 \%$ dope of $\mathrm{Zn}-\mathrm{Mg}$ 


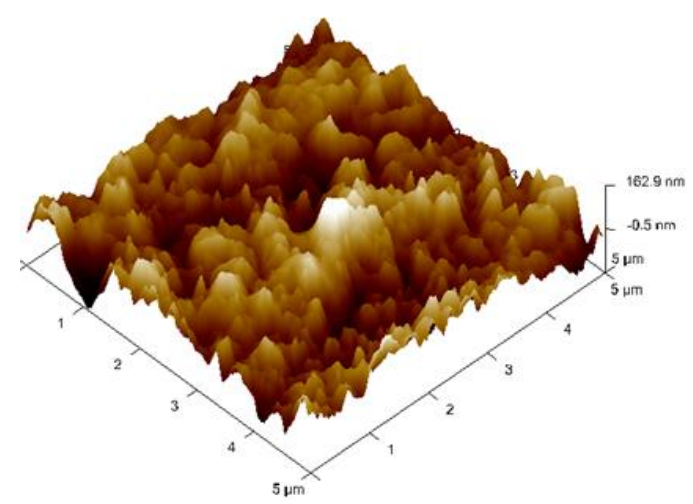

e) $10 \%$ dope of $\mathrm{Zn}-\mathrm{Mg}$

Fig. 6: AFM images of a) Undoped $\mathrm{V}_{2} \mathrm{O}_{5}$ b) $1 \%$ c) $3 \%$ d) $5 \%$ e) $10 \% \mathrm{Zn}$-Mgco-doped $\mathrm{V}_{2} \mathrm{O}_{5}$ thin films

The average surface roughness from the AFM images study (In figure6) shows an increasein approximateroughness from $31.5 \mathrm{~nm}$ to $69.4 \mathrm{~nm}$ with $\mathrm{Zn}$-Mgco-doping. The presence of ' $\mathrm{O}$ ' vacancy present in the films is responsible for the high surface roughness. The change insharp grain shapes to smooth grain size with the increased co-doping is also evident from FESEM images.

\section{CONCLUSIONS}

The thin films usingthe spray pyrolysis technique is adopted for fabricating undoped and Zn-Mgco-doped $\mathrm{V}_{2} \mathrm{O}_{5}$ films. The $\mathrm{Zn}$-Mgco-doping effect in $\mathrm{V}_{2} \mathrm{O}_{5}$ thin films is very much influential on the structural and morphology of thin films and enhancement in linear optical properties have been observed.The XRD indicate the polycrystalline nature of films with orthorhombic phasealongthe plane (200). The images of FESEM clarify that the undoped film is nonhomogeneouscompared to the co-doped films, which is evident from surface roughness values. The prepared compositionsof the film ensure theexpected elements of the films. The $\mathrm{Zn}-\mathrm{Mg}$ co-doping increases the surface roughness of the films. The bandgap energy found to bevarying about $7 \%$ with the different co-doping levels of $\mathrm{Zn}-\mathrm{Mg}$. The results obtained from these studies suggests that the $\mathrm{Zn}-\mathrm{Mg}$ co-doped on $\mathrm{V}_{2} \mathrm{O}_{5}$ films are suitable for low band energy andgas sensor-basedapplications.

\section{Acknowledgement}

The author Sandesh Kumar Rai would like to thank NMAMIT,Nitte, Indiafor spray pyrolysis research facilities and study support. Authors are grateful to Mangalore University-India--DST-PURSE laboratory for FESEM facilities and MIT, Manipal, India for XRD and AFM facilities.

\section{References}

1. H. S. Nalwa, Editor, Encyclopedia of Nanoscience and Nanotechnology, 1-10 Volumes American Scientific Publishers, Los Angeles, USA (2004).

2. A. Umar, Editor, Encyclopedia of Semiconductor Nanotechnology, Vols. 1-7, American Scientific Publishers, Los Angeles, USA (2017).

3. D. Wang, J.Yuan, Y. Zhou, H. Li, L. Chen and C. Song, Sci. Adv. Mater. 9, 2096 (2017).

4. R. Singh, E. Singh and H. S. Nalwa, RSC Adv., 7, 48597 (2017).

5. T. Kudo, Y. Ikeda, T. Watanabe, M. Hibino, M. Miyayama, H. Abe and K. Kajita. Sol. State Ionics 152, 833(2002).

6. A. Legrouri, T. Baird, and J. R. Fryer. J. Catalysis 140, 173 (1993).

7. G. T. Kim, J. Muster, V. Krstic, J. G. Park, Y. W. Park, S. Roth and M. Burghard. Appl. Phys. Lett. 76, 1875 (2000).

8. Q. Zhang, Q. Zhou, X. Yin, H. Liu, L. Xu, W. Tan, and C. Tang, Sci. Adv. Mater. 9, 1350-1355 (2017)

9. H. Song, C. Zhang, Y. Liu, C. Liu, X. Nan and G. Cao, J. Power Sources 294, 17 (2015).

10. G. P. Patil, V. S. Bagal, M. A. More, D. S. Joag, N. S. Gajbhiye, K. Dewangan and P. G. Chavan, J. Nanoelectron. Optoelectron. 12, 286 (2017).

11. Ji, D. Liu, C. Zhang, L. Yang, H. Cheng, and W. Zheng, 9, 861-867 (2017). 
12. A. E. Bulgurcuoglu, F. P. Gökdemir, O. Özdemir and K. Kutlu, J. Nanoelectron. Optoelectron. 12, 146 (2017).

13. Y. Tang, A. Tang, J. Ouyang and Y. Zhang, Mater. Focus 6, 501 (2017).

14. S. Ebrahimiasl, R. Seifi, R. E.Nahli and A. Zakaria, Sci. Adv. Mater. 9, 2045 (2017).

15. V. B. Chanshetty, K. Sangshetty, G. Sharanappa, V. Dhanalakshmi and R. Anbarasan, Int. J. Eng. Res. Appl. 2, 611 (2012).

16. [16] E. Mauro, R. Díaz, C. Force, E. Comini, T. Andreu, R. R. Zamani, J. Arbiol, P. Siciliano, G. Faglia and J. R. Morante, J. Phys. Chem. C 117, 20697 (2013).

17. G. Gu, M. Schmid, P. W. Chiu, A. Minett, J. Fraysse, G. T. Kim, S. Roth, M. Kozlov, E. Muñoz and R. H. Baughman, Nature Mater. 2, 316 (2003).

18. Singh N,UmarA,SinghN,FouadH,AlothmanOY,HaqueFZ, Materials Research Bulletin (2018).

19. H. Katayama-Yoshida, T. Nishimatsu, T. Yamamoto and N. Orita, J. Phys.: Condens. Matter 13(40), 8901(2001)

20. Jingzhao Zhang, KinfaiTse, Manhoi Wong, Yiou Zhang, Junyi Zhu, Front. Phys. 11(6), 117405 (2016).

21. Charishma, A. Jayarama, V. Veena Devi Shastrimath, R. Pinto, Sahyadri Int. J. Res. 3 (1) (2017) 37-46

22. Raghavendra Bairy, Parutagoudashankaragouda Patil, Shivaraj R. Maidur, Vijeth H, Murari M. S.and Udaya Bhat K., RSC Advances, 9, (39) (2019) 22302 - 22312.

23. SandeshkumarRai, Rajesh Rai, RaghavendraBairy, Jayarama A, M.S.Murari,R.Pinto,MaterialsTodayProceedings,35(2021)469-473

24. J. Tauc, Amorphous and Liquid Semiconductors, Plenum Press, New York (1974) 159. 